\title{
BORRELIA BURGDORFERI IN TICKS AND DOGS IN THE PROVINCE OF VOJVODINA, SerBiA ${ }^{1}$
}

\author{
SAVIĆ S.*, VIDIĆ B.*, LAZIĆ S.*, LAKO B.**, POTKONJAK A.** \& LEPŠANOVIĆ Z.**
}

\section{Summary:}

Lyme disease is a tick borne zoonotic infection, caused by Borrelia burgdorferi s.I. bacteria. For the transmission of the disease, the presence of ticks is a prerequisite. Lyme borreliosis mostly occurs in people and dogs, but it may occur in other animals. Ticks which carry B. burgdorferi s.I. in Serbia are of the lxodes ricinus specis. In Serbia, Lyme disease was detected for the first time in the late '80-es. In dogs, clinical symptoms may occur even months after a tick bite, and include weakness, lymphadenopathy, fever, lameness, arthritis, etc. In our survey, we have observed tick and dog populations in the province of Vojvodina (northern part of Serbia). I. ricinus ticks were collected and examined for the presence of B. burgdorferi s.l. in several chosen locations. In addition, blood samples were collected from house dogs and pets from the same locations, and analyzed for the presence of antibodies specific for B. burgdorferi s.l. The results showed a mean infection of ticks of $22.12 \%$, and a mean seroprevalence of lyme disease in dogs of $25.81 \%$. We conclude that in Vojvodina there is an actual risk of Lyme borreliosis for other animals and humans, because of the persistence of B. burgdorferi s.l. in both tick and dog populations.

KEY WORDS: Borrelia burgdorferi, Lyme borreliosis, diagnosis, Ixodes ricinus, tick, dog.
Résumé : BORRELIA BURGDORFERI CHEZ LES TICQUES ET LES CHIENS DE LA PROVINCE DE VOÏVODINe, SERBIE

La maladie de Lyme est une zoonose transmise par les tiques, due à l'infection par des bactéries Borrelia burgdorferi s.l. La présence de tiques est nécessaire à la transmission de la maladie. La borréliose de Lyme touche l'homme et le chien, mais elle peut aussi survenir chez d'autres animaux. Ixodes ricinus est la tique vectrice de B. burgdorferi s.I. en Serbie, où la maladie de Lyme a été détectée pour la première fois à la fin des années 1980. Chez le chien, les symptômes cliniques, qui peuvent survenir des mois après une morsure de tique, sont une asthénie, une lymphadénopathie, de la fièvre, une boiterie, de l'arthrite, etc. L'étude a porté sur les populations de tiques et de chiens de la province de Voïvodine, au nord de la Serbie. La présence de B. burgdorferi s.l. a été recherchée chez des I. ricinus collectés dans trois zones prédéterminées. La présence d'anticorps spécifiques dirigés contre B. burgdorferi a été recherchée dans des échantillons de sang de chiens et d'autres animaux de compagnie des trois mêmes zones. La prévalence moyenne de l'infection chez les tiques est de $22,12 \%$ et la séroprévalence moyenne de la maladie de Lyme est de 25,81\% chez les chiens. En conclusion, il existe dans la province Voivodine un risque de borréliose de Lyme chez l'animal et I'homme en raison de la présence persistante de B. burgdorferi s.l. tant dans les populations de tiques que de chiens.

MOTS CLÉS : Borrelia burgdorferi, borréliose, maladie de Lyme, diagnostic, Ixodes ricinus, tique, chien.

In addition to humans, the disease can often be found in dogs and sometimes in other domestic animals. Lyme disease is a systemic, infectious zoonotic disease, caused by the spirochete Borrelia burgdorferi s.l. It is primarily transmitted by ticks from the Ixodidae family (Burgdorfer, 1989). In Serbia, as elsewhere in central Europe, Lyme disease is transmitted by Ixodes ricinus (Perng et all., 1991) ticks (Fig. 1). Infection of the host occurs during the blood meal of a vector (tick), infected with a pathogenic strain of $B$. burgdorferi s.l. So far, 13 strains of Borrelia burgdorferi s.l. have been identified, three of which are pathogenic for humans and animals. These include B. burgdorferi sensu stricto, B. afzelii and B. garinii (Barbour \& Hayes, 1986). The distribution and presence of pathogenic genospecies of $B$. burgdorferi s.l. in ticks in Serbia, as well as their influence on clinical manifestations of Lyme disease in dogs, is yet to be evaluated.

** School of Agriculture Novi Sad, Dept of Veterinary Medicine, Trg

D. Obradovića, Novi Sad, Serbia.

***: Military Medical Academy (VMA), Institute for Epidemiology, Crnotravska 17, Belgrade, Serbia.

Correspondence: Sara Savić, Ms, DVM, Scientific Veterinary Institute "Novi Sad", Rumenacki put 20, 21000 Novi Sad, Serbia.

Tel.: +381214895330 - Fax: +38121518544 - Mob: +381638488469 E-mail: sara@niv.ns.ac.rs

${ }^{1}$ This article is based on an oral presentation given at the international conference "Parasitic zoonoses in present day Europe", Belgrade, 18-20 November 2009. 
Ticks are mostly found in public parks, close to big cities, and their survival is determined by their ability to complete the entire life cycle, including the necessary hosts and developmental stages (Pejchalova, 2007). Lately, ticks have been found in children playgrounds, school and kindergarten yards and also in dog playgrounds within parks.

During the last five years, surveys showed that ticks in Serbia are infected with $B$. burgdorferi s.l. at a rate of 25-30\%, depending on the region (Milutinović et al., 2004; Milutinović et al., 2008, Cekanac et al., 2009). Also, a number of clinical cases of Lyme disease was registered in humans and dogs (Dmitrović, 1996; SavićJevđenić et al., 2008). Accurate data on the possible relation between the number of infected dogs and the percentage of ticks infected with B. burgdorferi s.l. within particular regions are still lacking. According to one study, the percentage of ticks infected with $B$. burgdorferi s.l. in the province of Vojvodina ranges from 25-28\% (Savić et al., 2007). An analysis of ticks in selected urban regions performed during a three-year period revealed an infection rate of $25 \%$ (Jurišić, 2008). In dogs, ticks are most likely to be found near the eye, exterior and interior surface of the ear, around the nose and neck and also on the back, under the front and back legs and between fingers (Skotarczak, 2007). After a natural infection of dogs with $B$. burgdorferi s.l. pathogenic strains, clinical signs are found in only $5 \%$ of infected animals. The clinical signs include loss of appetite, weakness, lymphadenopathy, and fever. Later on, 2-5 months after the tick bite, intermittent lameness and mono- or oligoartritis may occur, which last up to a few weeks. Acute and subacute arthritis may develop, which can persist or reoccur even after treatment, and often expand to the chronic form of Lyme arthritis.

Since there are no pathognomonic clinical signs, diagnosis of Lyme disease in dogs relies on laboratory diagnostic procedures. Most often it is based on the detection of $B$. burgdorferi specific antibodies in the serum. A variety of serological methods may be used, including complement fixation (CF), ELISA, Western blot, immunofluorescence and immunochromatographic fast tests. A study performed on hunting dogs revealed a seroprevalence of 15-20\%, many of which did not show any clinical symptoms (Savić et al., 2008). To interpret serological results, insight into the local epidemiological situation is thus very important (Littman, 2006).

\section{MATERIAL AND METHODS}

Txodes ricinus ticks were collected in the field with a white flag of $1 \mathrm{~m}^{2}$, from the meadow and forest vegetation during the tick season (end of March beginning of June, and end of August - end of October).
Ticks were picked during a three year period (20062008) within four regions of Vojvodina (Ada-Mol region, Novi Sad region, Fruška gora region and Novi Bečej region). The gender and life cycle stage were determined morphologically, and abdominal content examined for the presence of $B$. burgdorferi s.l. by dark field microscopy. The isolation of autochthonous strains of $B$. burgdorferi s.l. from ticks was performed in selective media BSK-H complete medium, with 6\% rabbit sera (Zuckert, 2007). The tubes with selective media and inoculated tick content were incubated at $33^{\circ} \mathrm{C}$ and checked every seven days by dark field microscopy for the growth of B. burgdorferi s.l. Genotyping of Borrelia isolates was done by PCR. For preparation of the samples, 1-3 ml of isolated Borrelia culture in BSK media was centrifuged for 5 minutes. Supernatant was removed and the sediment washed first in PBS pH 7,0 and then in distilled water. The samples were then cooked for 15 minutes in boiling water. After another centrifugation, the supernatant was moved to new tubes and then kept at $-20^{\circ} \mathrm{C}$. The multiplication process was done by mixing $5 \mu \mathrm{l}$ of prepared sample and $45 \mu \mathrm{l}$ of PCR mix $(5 \mu \mathrm{l}$ $10 \mathrm{X}$ concentrated buffer (Applied Biosystems), $1,5 \mathrm{mM} \mathrm{MgCl}_{2}, 100 \mu \mathrm{M}$ of each dATP, dGTP, dCTP and TTP, 15 pmol of primer and 1,5 U Taq DNA polymerase. The "50bp DNA Ladder" was used as a marker of known molecular weight. PCR products were electrophoresed on $1.5 \%$ agarose gel and stained with ethidium bromide. The order of primer nucleotides was taken from Kupier et al (Kupier et al., 1994).

In addition, blood samples were drawn from 486 dogs living in the same region where the ticks were collected. Most of them were house dogs and pets, both males and females, of different breeds, from 2 to 14 years of age. Blood samples were analyzed by ELISA and Western blot for the presence of B. burgdorferi specific antibodies. ELISA (recomWell Borrelia canis IgG, Mikrogen, Germany) was performed according to the manufacturer's instructions. This test contains recombinant antigens for the detection of IgG antibodies against $B$.

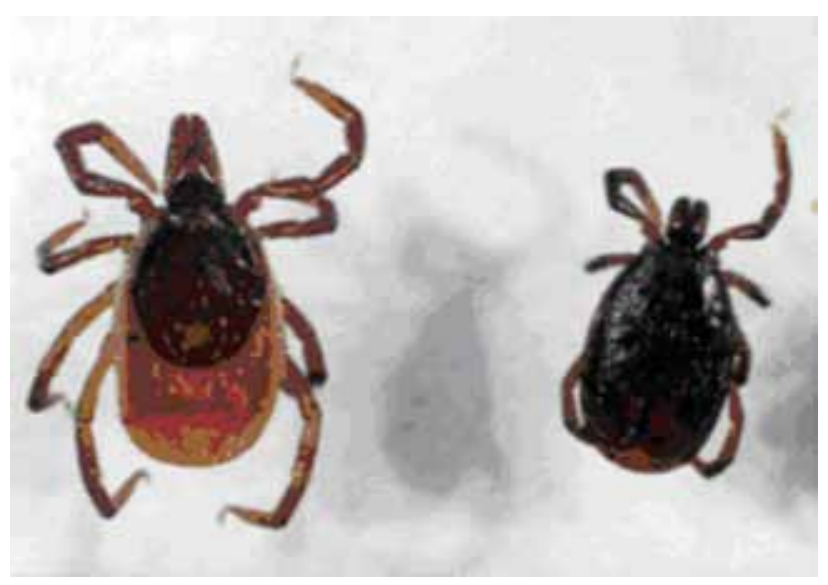

Fig. 1 - I. ricinus, adults female (left) and male (right), Jurišić (2008). 
burgdorferi s.l., B. garinii, B. afzelii. Western blot (recomBlot Borrelia Canis IgG, Mikrogen, Germany) was also performed according to the manufacturer's instructions. The antigens used in this test include the highly specific $B$. burgdorferi antigens p100, p39, p18, and p41 (flagelin), as well as the OspA and OspC outer surface proteins. OspC protein from all three genospecies can be found (B. burgdorferi s.l., B. garinii and $B$. afzelii), and also the ones from two different strains of B. garinii (strain T25/OspA serotipe 7 and strain 20047/ OspA serotipe 0), named as B. garinii 1 and B. garinii 2 .

\section{RESULTS AND DISCUSSION}

D uring the three-year study period, a total of 1,224 ticks were collected from different locations in Vojvodina. The dominant species was Ixodes ricinus, accounting for $62 \%$ (764 ticks) of all collected ticks. All ticks were analyzed for the presence of B. burgdorferi s.l. (Table I).

The seroprevalence of $B$. burgdorferi s.l. infected ticks in the territory of Vojvodina during the survey period (2006-2008) was $22.12 \%$, but ranged widely, from $11 \%$ to $29 \%$, depending on location and year. In 2008 , the seroprevalence of $B$. burgdorferi s.l. in ticks was $23.8 \%$, which is moderate compared to other European countries, where it ranges from 11-12\% in Spain and Portugal, $14,8 \%$ in the Czech Republic and $19 \%$ in Switzerland, to $45 \%$ in some parts of Croatia and even to $60 \%$ in the Lublin region in Poland (Pejchalova, 2007, Moran Cadenas et al., 2007). The results showed that the distribution of infected ticks was not the same in the whole Province of Vojvodina. In 2008, there was one region (region of Novi Bečej) where none of the collected ticks were infected. In this particular region there were no seropositive dogs either.

Isolation of B. burgdorferi s.l. was attempted from tick pools, pooled according to gender and life cycle stage. From the total of 26 pools, the growth of spirochetes in the BSK-H media (Sigma) was noticed in four (15\%). These pools were named after the locations, or the marks of the locations where they were picked. In pool 1,2 and 3 the growth of spirochetes was spotted after 14 days, whereas in the fourth pool, the growth began after 21 days. The final concentrations of isolated strains
M $\begin{array}{llll}1 & 2 & 3 & 4\end{array}$

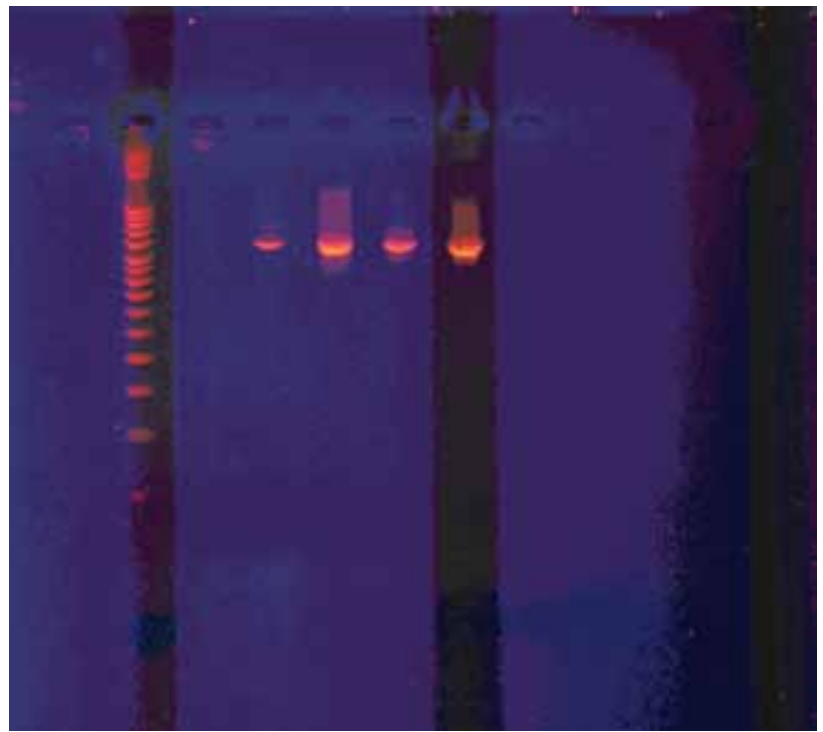

Fig. 2 - Species specific PCR of Borrelia burgdorferi sensu lato isolates; Lines: M, DNA size marker, 50 bp DNA ladder; 1 (tick pool 1), isolate amplified with primers specific for Borrelia burgdorferi sensu stricto; 2-4, isolates (Tick pool 2-4) amplified with primers specific for Borrelia afzelii.

of B. burgdorferi s.l. were from $32-76 \times 10^{5}$ B. burgdorferi / $\mathrm{ml}$ culture for four different pools.

$B$. burgdorferi s.l. is very difficult to culture, demanding in conditions, and bacteria undergo certain changes in order to adjust to in vitro growth. We therefore did not achieve growth of $B$. burgdorferi s.l. from each sample. It is known that the number of spirochetes in the tick sample and the type of media used, along with the aseptic conditions needed for working with borrelia, can very much influence in vitro growth (Ružić-Sabljić et al., 2006).

Genotypization of B. burgdorferi s.l. isolates from $I$. ricinus ticks showed the following results:

- tick pool 1: B. burgdorferi sensu stricto (specific fragment 575bp);

- tick pool 2: Borrelia afzelii (specific fragment 591bp); - tick pool 3: Borrelia afzelii (specific fragment 591bp); - tick pool 4: Borrelia afzelii (specific fragment 591bp). From the total of 486 dog blood samples obtained from dogs living in the regions where $11-29 \%$ of ticks were infected with B. burgdorferi s.1., $25.5 \%$ were found to

\begin{tabular}{|c|c|c|c|c|c|c|}
\hline Year & $\begin{array}{c}\text { Total No } \\
\text { collected ticks }\end{array}$ & $\begin{array}{c}\text { Total No } \\
\text { \& } \% \text { of } \\
\text { I. ricinus }\end{array}$ & $\begin{array}{c}\text { No \& } \% \\
\text { of adult females }\end{array}$ & $\begin{array}{c}\text { No \& } \% \\
\text { of adult males }\end{array}$ & $\begin{array}{c}\text { No \& \% } \\
\text { of nymphs }\end{array}$ & $\begin{array}{c}\text { No \& } \% \\
\text { of ticks infected } \\
\text { with } \text { B.b. } \text { s.l }\end{array}$ \\
\hline 2006 & 386 & $232(60 \%)$ & $109(47 \%)$ & $102(44 \%)$ & $21(9 \%)$ & $44(18.9 \%)$ \\
\hline 2007 & 479 & $302(63 \%)$ & $173(57 \%)$ & $93(31 \%)$ & $36(12 \%)$ & $94(19.6 \%)$ \\
\hline 2008 & 359 & $230(64 \%)$ & $90(39 \%)$ & $119(52 \%)$ & $21(9 \%)$ & $55(23.8 \%)$ \\
\hline TOTAL & 1,224 & $764(62 \%)$ & $372(49 \%)$ & $314(41 \%)$ & $78(10 \%)$ & $169(22.12 \%)$ \\
\hline
\end{tabular}

Table I. - The annual number of collected ticks infected with Borrelia burgdorferi s.1. during the period 2006-2008. 
Total No No (\%) of positive samples to B.b. s.l by ELISA
No (\%) of positive samples to B.b. s.l. by Western blot

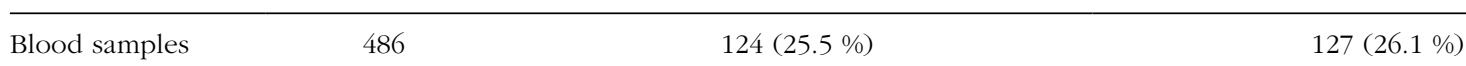

Table II. - Dog blood sera analysis for the presence of specific antibodies against Borrelia burgdorferi s.l. by ELISA and Western blot test.

be positive for B. burgdorferi s.1. by ELISAand $26.1 \%$ by Western blot (Table II).

The owners of pet dogs, especially in urban locations, are not sufficiently aware of the risk nor are familiar with the possible consequences of a tick bite, so they often do not use any products for prevention of tick bites. Also, owners of pet dogs are frequently poorly informed about the number of ticks infected with $B$. burgdorferi s.l. in their region and also about the risk these ticks represent for their dogs and themselves.

Abundant literature data report that the epidemiological profile of dog borreliosis represents a potential indicator of the risk for human borreliosis in a certain region (Skotarczak, 2007). Translated to the analyzed regions, the results of this study indicate that in Vojvodina there is a risk for human borreliosis. Tick control is a major measure for the prevention of borreliosis, and to that purpose tick repellents for pets and acaricides (amitraz, permetrin) for animals and the environment should be used, as well as prompt mechanical removal of the tick from the skin (Shaw, 2008).

The most friendly conditions for ticks are the regions between forests and meadows and they depend on geographic locations, altitude, flora and fauna and the presence of hosts. The most important factor that influences the survival of ticks in a region is air humidity. In mixed woods, the largest population of ticks is in places where humidity reaches $70-80 \%$. The survival of a tick in a certain region depends on the possibility to complete its life cycle (Pejchalova, 2007). In Northern Serbia, humidity can be very high, so active ticks were found even in November, when the outdoor temperature was below $8{ }^{\circ} \mathrm{C}$, but the humidity was over $80 \%$ (Jurišić, 2008).

Infection with $B$. burgdorferi s.l. is present in the tick population in Vojvodina, at an average rate of $22.12 \%$; however, the results showed it ranged from 11-29\%, depending on the year and region. In addition, infection with $B$. burgdorferi s.l. is present among the dog population in Vojvodina, at a rate of $25.5 \%$ as detected by ELISA and $26.1 \%$ as detected by Western blot. Among the dog population living in the region where ticks infected with $B$. burgdorferi s.l. were found, there are dogs with positive serological findings for Lyme borreliosis, even though none of the clinical signs of the disease can be seen. Thus, it may be concluded that in Vojvodina there is a real risk of Lyme borreliosis in humans, because of the persistence of the disease in both tick and dog populations.

\section{ACKNOWLEDGEMENTS}

his work was supported by a grant (TR 20115) from the Ministry of Science and Technological Development of Serbia. The authors are grateful to Professor Olgica Djurković-Djaković for guidance and kind help in the preparation of this manuscript, and to Professor Marija Milutinović for critical review of the text.

\section{REFERENCES}

Barbour A.G. \& HaYes S.F. Biology biology of Borrelia species. Microbiology Review, 1986, 50 (4), 381-400.

Burgdorfer W., Hayes S.F. \& CorWin D. Pathophysiology of the Lyme disease spirchete, Borrelia burgdorferi, in ixodid ticks. Review of infectious diseases, 1989, suppl 6, 1442-1450.

Cekanac R., Pavlović N., Gledović Z., Grgurević A., Stajković N., LEPŠANOVIĆ Z. \& Ristanović E. Prevalence of Borrelia burgdorferi in Ixodes ricinus ticks in Belgrade area. Vector borne Zoonotic Diseases, 2009, Dec 18 (Epub ahead of print).

DMitrović R. Lajmska bolest u Jugoslaviji (Lyme disease in Yugoslavia). Velarta, Belgrade, 1996.

JURIŠIĆ A. Krpelji-prenosioci uzročnika bolesti kod ljudi i Životinja (Ticks - vectors of the cause of diseases in humans and animals). Biblioteka Akademia, Zadužbina Andrejević, Belgrade, 2008.

Kuiper H., van Dam A., Spanjaard L., De Jongh B., Widjojokusumo A., Ramselaar T.C.P., Cairo I., Vos K. \& Dankert J. Isolation of Borrelia burgdorferi from biopsy specimens taken from healthy-looking skin of patients with Lyme borreliosis. Journal of Clinical Microbiology, 1994, 32 (3), 715-720.

Lako B., Dmitrović R., Drndarević D., Nanušević N., LaZarević N., Obradović M. \& ĐorĐević D. Our first experiences with serological diagnosis of Lyme disease. $9^{\text {th }}$ Yugoslavian-Italian Meeting on Infectious Diseases, Belgrade, 1998. Book of abstracts, 45.

LitTMAn MP. Lyme disease: What to do when the snap is positive. Proceedings of the North American veterinary conference, Orlando, Florida, 2006, Vol 20.

Milutinović M., Radulović Ž., Jovičić V. \& OrešČanin Z. Population dynamics and Borrelia burgdorferi infection rate of Ixodes ricinus ticks in the Belgrade area. Acta Veterinaria, 2004, 54 (2-3), 219-225.

Milutinović M., Masuzawa T., Tomanović S., Radulović Ž., FuKui T. \& Окамото Y. Borrelia burgdorferi sensu lato, 
Anaplasma phagocytophilum, Francisella tularensis and their co-infections in host seeking Ixodes ricinus ticks collected in Serbia. Experimental \& Applied Acarology, 2008, 45, 171-183.

Moran Cadenas F., Rais O., Humair P.F., Douet V., Moret J. \& GERN L. Identification of host bloodmeal source and Borrelia burgdorferi sensu lato in field-collected Ixodes ricinus ticks in Chaumont (Switzerland). Journal of Medical Entomology, 2007, 44 (6), 1109-1117.

Pejchalova K., Žakovska A., Mejzlikova M., Halouzka J. \& DENDIS M. Isolation, cultivaton and identification of Borrelia burgdorferi genospecies from Ixodes ricinus ticks from the city of Brno, Czech republic. Annals of Agricultural and Environmental Medicine, 2007, 14, 75-79.

RuŽić-Sabljić E., Lotrič-Furlan S., Maraspin V., Cimperman J., Logar M., JuRCA T. \& STRLE F. Comparison of isolation rate of Borrelia burgdorferi sansu lato in MKP and BSK-II medium. International Journal of Medical Microbiology, 2006, 296 (1), 267-273.

Savić-JevĐenić S., Grgić, Ž., Vidić B. \& Petrovic A. Lyme disease - the great imitator. Biotechnology in Animal Husbandry, 2007, 23 (5-6), 215-221.

SAVIĆ-JevĐenić S., Vidić B., Grgić Ž., JurišIć A. \& LaKo B. Lyme borreliosis in hunting dogs. Book of Proceedings, VI international Conference on ticks and tick-borne pathogens, TTP-6, Buenos Aires, Argentina, 2008, 317.

SHAW S.E. Understanding transmission of infection by ticks and new strategies for control. Proceedings of the $33^{\text {rd }}$ World Small Animal Vetetrinary Congress, Parasitic diseases, Dublin, Ireland, 2008, 23, 543-545.

SKOTARCZAK B. Lyme borreliosis in dogs. Book from Peter van Nitch: Research on Lyme disease. Nova Science Publishers, Inc, 2007, 69-81.

ZUCKERT W.R. Laboratory maintance of Borrelia burgdorferi. Current protocols in microbiology, Copyright 2007 by John Wiley \& Sons, Inc, 2007, 12C1.1. - 12C1.10.

Reçu le 17 juin 2010 Accepté le $1^{\text {er }}$ juillet 2010 